\title{
Analysis of Three-Dimensional Morphological Differences in the Mandible between Skeletal Class I and Class II with CBCT Fixed- Point Measurement Method
}

\author{
Qiang Dong $\mathbb{D},{ }^{1,2}$ HaoYu Shi $\mathbb{D}^{3},{ }^{3}$ Qi Jia $\mathbb{D}^{3},{ }^{3}$ Yueyi Tian $\mathbb{D}^{3},{ }^{3}$ Keqian Zhi $\mathbb{D},{ }^{1}$ and Lu Zhang $\mathbb{D}^{1}$ \\ ${ }^{1}$ Department of Stomatology, The Affiliated Hospital of Qingdao University, Qingdao, 266003 Shandong, China \\ ${ }^{2}$ School of Stomatology of Qingdao University, Qingdao, 266003 Shandong, China \\ ${ }^{3}$ The Conversationalist Club, School of Stomatology, Shandong First Medical University, Tai'an, 271016 Shandong, China
}

Correspondence should be addressed to Keqian Zhi; zhikeqianqd@qdu.edu.cn and Lu Zhang; 815808740@qq.com

Received 10 March 2021; Revised 21 March 2021; Accepted 24 April 2021; Published 7 May 2021

Academic Editor: Shi-Xun Ma

Copyright ( 2021 Qiang Dong et al. This is an open access article distributed under the Creative Commons Attribution License, which permits unrestricted use, distribution, and reproduction in any medium, provided the original work is properly cited.

\begin{abstract}
This study was aimed at determining the three-dimensional differences in the mandible morphology between skeletal class I and II patients, at exploring the pathogenic mechanisms and morphological characteristics of skeletal class II, and at providing clinical references. The subjects were assigned to two groups according to the size of ANB angle: skeletal class I $\left(2^{\circ}<\right.$ ANB angle $\left.<5^{\circ}\right)$ and skeletal class II $\left(5^{\circ}<\mathrm{ANB}\right.$ angle $\left.<8^{\circ}\right)$. After cone-beam computed tomography (CBCT) scanning, 31 landmarks and 25 measurement items were determined by In Vivo Dental 5.1 software (Anatomage, CA) for statistical analysis. The results were as follows: Co-Go, Go-Me, and CdM-CdD in skeletal class II cases were smaller than those in skeletal class I, and GoR-Me-GoL, GoR-Me-CoL, and, Ig-Men were larger than those in skeletal class I cases. In conclusion, there were significant differences in the three-dimensional morphology of the mandible between skeletal class I and class II patients. The vertical growth of the ramus, the horizontal growth of the mandibular body, and the condyle in skeletal class II patients were smaller than those in skeletal class I cases. In skeletal class II, the growth of the anterior part of the mandible in the vertical direction was larger than that in skeletal class I, and the shape of the mandible was more extended.
\end{abstract}

\section{Introduction}

Skeletal class II malocclusion is a common jaw deformity in the clinic, with a prevalence rate of approximately $20 \%$. It is characterized by abnormal mandibular morphology and abnormal sagittal position between the maxilla and mandible [1]. The mandible is an important component of the craniofacial complex, in the lower one-third of the face. Genetic and environmental factors impact mandibular size and morphology easily, which play an important role in the esthetic appearance and function of the maxillofacial region. Uncoordinated facial contour caused by the mandible is one of the most common causes for patients seeking orthodontic treatment [2]. Therefore, orthodontists should pay close attention to the mandibular size, morphology, position, and rotation angle to select an appropriate treatment plan [3].
CBCT has the advantages of fast scanning, low effective radiation dose, simple procedural steps, etc. Its accuracy of the three-dimensional reconstruction is high, with a true one-to-one measure of craniofacial anatomy. It can be directly measured on three-dimensional reconstructed images, similar to the anatomical measurement [4-7]. The extensive application of CBCT in the clinic and the increasingly optimized third-party image processing software significantly improve the measurement of craniomaxillofacial structures, providing more accurate and comprehensive information [8].

The mandible is a three-dimensional structure with an irregular shape. Two-dimensional images cannot fully and accurately reflect the actual situation of three-dimensional structures. Thus, in clinical orthodontics, three-dimensional reconstruction and measurement analysis of the mandible 
is of great significance [9]. Despite some achievements in the three-dimensional morphology of the mandible, the data are still relatively scarce. This study was aimed at determining the three-dimensional mandibular morphology in patients with skeletal class I and class II malocclusion, at exploring the differences between them, and at providing a reference for the pathogenesis, classification, and treatment of skeletal class II malocclusion.

\section{Materials and Methods}

2.1. Case Selection. The total sample (72 volunteers) was obtained at the Orthodontic Department, Affiliated Hospital of Qingdao University.

The inclusion criteria were as follows: (1) Han nationality aged 18-25 years, (2) facial symmetry, (3) complete dentition, and (4) clear and complete CBCT images.

The exclusion criteria were as follows: (1) history of oral and maxillofacial trauma, (2) history of orthodontic or orthognathic treatment, (3) severe soft and hard tissue lesions in the maxillofacial region, (4) systemic diseases, and (5) blurred, distorted, and overlapping CBCT images with affects, affecting the identification and measurement.

The subjects were divided into class I or class II skeletal patterns, according to the ANB angle.

Skeletal class $I\left(2^{\circ}<A N B\right.$ angle $\left.<5^{\circ}\right): 36$ cases, including 18 males and 18 females.

Skeletal class $I I\left(5^{\circ}<A N B\right.$ angle $\left.<8^{\circ}\right)$ : 36 cases, including 18 males and 18 females.

2.2. Scanning and Reconstruction. The CBCT images of the patients were captured by a CBCT unit (Pax-Zenith3d, EWOO-VATECH, Korea). The subjects' facial midline was adjusted perpendicular to the floor, the head position was fixed, and the lips were occluded and closed naturally, breathing calmly without swallowing. The source data of volunteers were obtained and stored in a DICOM format: scanning range: wide field; scanning conditions: tube voltage $90 \mathrm{kV}$ and tube current $4 \mathrm{~mA}$. DICOM files were imported into the same orthodontic workstation computer installed with In Vivo Dental 5.1 software to reconstruct the image data.

2.3. Determination of Mark Points and Measurement Items. Ideal landmarks should be anatomic landmarks that are easy to locate and relatively stable, reflecting the morphological characteristics of the mandible. Through literature review and analysis, 31 commonly used three-dimensional measurement landmarks of the mandible were selected. It includes 5 coordinate system points, 6 single points, and 20 paired points (Table 1).

According to the relevant literatures, a total of 25 line distance and angle measurements were selected to describe the morphological characteristics of the mandible, of which 10 measurements were used to describe the characteristics of the mandibular ramus, and 8 measurements were used to describe the characteristics of condyle and coracoid process [10-12]. The line distance is measured in " $\mathrm{mm}$ " and the angle is measured in "o" (Table 2).
2.4. Three-Dimensional Items. A 3D analysis module of In Vivo Dental 5.1 software was used to fix 3D points. Turn on the "slice locator" function to display the position of the marked points in the cross section, sagittal plane, and coronal plane. Adjusting the position by moving three-dimensional landmarks on the three sections and combining with the three-dimensional model of the head, the accuracy and reliability of the three-dimensional fixed point can be improved. The $3 \mathrm{D}$ positioning maps of some landmark points are shown in Figure 1.

2.5. Three-Dimensional Measurement. 25 measurement items were set in the 3D analysis module of In Vivo Dental 5.1 software. After the 3D fixed point was completed, set line distance and angle measurement values were automatically obtained. Each patient was measured twice by the same person with an interval of one week, and the average value of the two measurements was taken as the $3 \mathrm{D}$ measurement result (Figures 2-4).

2.6. Statistical Analysis. SPSS (IBM, USA) was used for statistical analysis. The statistical differences between class I and class II, between class I men and class II men, and between class I women and class II women were compared. ShapiroWilk test was used to determine whether the data were in accordance with normal distribution, and independent sample $t$-test was used for the difference. $P<0.05$ indicates a significant difference.

\section{Result}

3.1. Skeletal Class I and Class II. There were six items with statistical difference between skeletal class I and skeletal class II (Table 3). Co-Go, Go-Me, and CdM-CdD of skeletal class II were smaller than those of skeletal class I. Ig-Men, GoRMe-GoL, and CoR-Me-CoL were larger than those of skeletal class I. There was no significant difference in other measurement items.

3.2. Skeletal Class I and Class II in Male. Go-Me and CdMCdD of skeletal class II were smaller than those of skeletal class I. Ig-Men and GoR-Me-GoL were larger than those of skeletal class I (Table 4).

3.3. Skeletal Class I and Class II in Female. Go-Me, Co-Go, CdM-CdD, and CdA-CdP in skeletal class II were smaller than those in skeletal class I (Table 5).

\section{Discussion}

4.1. Advantages of Three-Dimensional Measurement in the Mandible. Three-dimensional measurement technology includes laser scanning technology, structured light scanning technology, X-ray technology, and spiral CT scanning technology, which is widely used in clinical and scientific researches $[9,13-16]$. The early study of the mandible was mainly based on lateral cephalogram. Technological advances in CBCT appear to offer significant advantages in both quality and quantity of data representing true anatomy $[17,18]$. We can analyze morphological structure and 
TABLE 1: The abbreviations and definitions of the landmarks.

\begin{tabular}{|c|c|c|}
\hline Landmarks & Abbreviation & Definition \\
\hline \multicolumn{3}{|c|}{ Coordinate system points } \\
\hline Nasion & $\mathrm{N}$ & The most anterior point of the nasal frontal suture \\
\hline Right porion & Po-R & The uppermost point of right external auditory canal \\
\hline Right orbitale & Or-R & The lowest point of the right infraorbital margin \\
\hline Anterior nasal spine & ANS & The apex of the anterior nasal ridge \\
\hline Basion & $\mathrm{Ba}$ & The midpoint of the anterior edge of foramen magnum \\
\hline \multicolumn{3}{|r|}{ Single points } \\
\hline Sellar & $\mathrm{S}$ & The central point of the pituitary fossa \\
\hline A & A & $\begin{array}{l}\text { The most concave point of the bone between the point of anterior } \\
\text { nasal ridge and the point of superior alveolar margin }\end{array}$ \\
\hline $\mathrm{B}$ & B & $\begin{array}{l}\text { The most concave point of the bone between the point of the inferior } \\
\text { alveolar margin and the point of the anterior chin }\end{array}$ \\
\hline Gnathion & Gn & The midpoint between the anterior point of chin and the submental point \\
\hline Menton & Men & The lowest point of the chin \\
\hline $\operatorname{Ig}$ & Ig & The apex of alveoli between lower central incisors \\
\hline \multicolumn{3}{|r|}{ Paired points } \\
\hline Left gonion & Go-L & Posterior inferior point of left mandibular angle \\
\hline Right gonion & Go-R & Posterior inferior point of right mandibular angle \\
\hline Internal point of left condyle & Co-L & The uppermost point of the left condyle \\
\hline Internal point of right condyle & Co-R & The uppermost point of the right condyle \\
\hline External point of left condyle & CdML & The innermost point of the left condyle \\
\hline External point of right condyle & CdMR & The innermost point of the right condyle \\
\hline Anterior point of left condyle & CdAL & The most lateral point of the left condyle \\
\hline Anterior point of right condyle & CdAR & The most lateral point of the right condyle \\
\hline Posterior point of left condyle & CdPL & The last point of the left condyle \\
\hline Posterior point of right condyle & CdPR & The last point of the right condyle \\
\hline Apex of left coracoid process & Cc-L & The uppermost point of the left coracoid process \\
\hline Apex of right coracoid process & Cc-R & The uppermost point of the right coracoid process \\
\hline Left sigmoid notch & Sg-L & The lowest point of the left sigmoid notch \\
\hline Right sigmoid notch & Sg-R & The lowest point of the right sigmoid notch \\
\hline Left mandibular inflection & Ma-L & $\begin{array}{l}\text { The most concave and outermost point between left anterior edge } \\
\text { of ramus and mandibular body turning point }\end{array}$ \\
\hline Right mandibular inflection & Ma-R & $\begin{array}{l}\text { The most concave and outermost point between right anterior edge } \\
\text { of ramus and mandibular body turning point }\end{array}$ \\
\hline Left mental foramen & Mf-L & $\begin{array}{c}\text { The lateral superior point of the left mental foramen } \\
\text { on the anterior surface of the mandible }\end{array}$ \\
\hline Right mental foramen & Mf-R & $\begin{array}{l}\text { The lateral superior point of the right mental foramen } \\
\text { on the anterior surface of the mandible }\end{array}$ \\
\hline
\end{tabular}

position of the mandible in three-dimensional direction by using $\mathrm{CBCT}$, so as to better refer to the scientific research and clinical work in the field of orthodontics.

Accurate fixed location of anatomical landmarks is the premise of obtaining reliable analysis results. The threedimensional landmarks selected in this experiment are supported by previous literatures [19]. They are easy to determine, with rare variation, which can truly reflect the shape and structure of the mandible [10-12]. Point Co and other paired points are independent and related to each other. In the traditional two-dimensional measurement method, the images of these points are the superposition or the mean value of the two, which ignore part of the superposition or the mandible, causing loss of mandibular information. In this experiment, the paired points were marked separately to increase the transverse line distance of the mandible, such as GoR-GoL, MfR-MfL, and CdM-cDd, which reflected the horizontal characteristics of the mandible and obtained more comprehensive information to describe the characteristics of the mandible.

The three-dimensional measurement makes it possible to measure the items that cannot be measured on a two- 
TABLE 2: The line distance and angle measurements to describe the morphological characteristics of the mandible.

\begin{tabular}{|c|c|}
\hline \multicolumn{2}{|r|}{ Mandibular body } \\
\hline GoR-GoL & Mandibular body width \\
\hline MfR-MfL & Width between mental foramen \\
\hline Go-Ma (R/L) & Width between gonion \\
\hline Go-Me (R/L) & Mandibular body length \\
\hline Co-Gn (R/L) & Effective mandible length \\
\hline Ma-Ig (R/L) & Alveolar process length \\
\hline Ig-Men & Height of mandibular body \\
\hline GoR-Me-GoL & $\begin{array}{l}\text { The opening of mandibular body relative to } \\
\qquad \mathrm{Me}\end{array}$ \\
\hline Co-Go-Me (R/L) & Mandibular angle \\
\hline Cc-Ma-Ig (R/L) & Anterior angle of mandible \\
\hline \multicolumn{2}{|r|}{ Ramus of mandible } \\
\hline SgR-SgL & Width between sigmoid notch \\
\hline MaR-MaL & $\begin{array}{l}\text { Width between the mandibular inflection } \\
\text { points }\end{array}$ \\
\hline Co-Go (R/L) & Ramus height \\
\hline CoR-Me-CoL & $\begin{array}{l}\text { The opening of mandibular ramus relative to } \\
\text { Me }\end{array}$ \\
\hline Cc-Sg-Co (R/L) & Coracoid-sigmoid notch-condylar angle \\
\hline CoGo-Sag (R/L) & Anteroposterior inclination of ramus \\
\hline CoGo-Cor (R/L) & Mesial and distal inclination of ramus \\
\hline \multicolumn{2}{|r|}{ Condyle } \\
\hline CcR-CcL & Width between coracoid processes \\
\hline CoR-CoL & Width between condylar \\
\hline Co-Cc (R/L) & Distance between condyle and coracoid \\
\hline CdM-CdD (R/L) & Condylar width \\
\hline CdA-CdP (R/L) & Condylar thickness \\
\hline Co-Sg (R/L) & Condylar height \\
\hline $\begin{array}{l}\text { CdMCdD-Sag } \\
(\mathrm{R} / \mathrm{L})\end{array}$ & Anteroposterior inclination of condyle \\
\hline $\begin{array}{l}\text { CdMCdD-Cor } \\
(\mathrm{R} / \mathrm{L})\end{array}$ & Mesial and distal inclination of condyle \\
\hline
\end{tabular}

dimensional plain film. It can not only measure the line distance and angle on the same plane but also measure the distance between the point and plane, the angle of project between line and plane, etc. which greatly improves the richness of measurement. For example, in this experiment, the angle between the ramus and horizontal plane projected on the median sagittal plane represents its anteroposterior inclination (-Sag), and the angle between the ramus and horizontal plane projected on the coronal plane represents its mesial and distal inclination (-Cor).

In the future, a three-dimensional cephalometric method can be established to help orthodontists get better diagnosis and treatment plan. However, it should be noted that the significance of many measurement items has changed after the transformation from two-dimensional measurement to three-dimensional measurement. The traditional cephalometric measurement is the result of the projection of the structure to the median sagittal plane, which reflects a single-dimensional relationship. In the three-dimensional measurement, most of the measurement items are not in one plane, which often reflect the relationship between two or even three dimensions [20]. The reference significance and normal value of each measurement item in threedimensional cephalometry need to be further studied [20].

4.2. The Clinical Significance of Mandibular Morphology Difference between Skeletal Class I and Skeletal Class II. Skeletal class II malocclusion is a common malocclusion in the clinic, characterized by deep overbite of the anterior teeth, open lips, exposed teeth, maxillary protrusion, and mandibular retrusion, seriously affecting the facial appearance and chewing functions [21].

Highly complicated environmental and genetic factors are involved in the complex interplay controlling mandibular growth [22], such as heredity, rotation of the anterior cranial fossa, tooth eruption, pharyngeal growth, lip growth, cheeks and the tongue, changes in muscle behavior, nasal airway growth, changes in swallowing patterns, and bad oral habits. Karlsen believes that the shape of the mandible is related to growth type, the spatial direction of muscles, and the direction of the bite force [23]. The occlusal pressure produced by masticatory muscles affects the size and shape of the mandible, especially the length of the mandibular body and the height of the ramus [24]. Larger masseter and medial pterygoid muscles have a higher resting metabolic activity, keep bone under more tension, and grow in a more horizontal direction. As the mandibular angle increases, muscle metabolic activity decreases, and the decrease in bite force, muscle function, and biological efficiency might lead to decreased mandibular volume [25]. Furthermore, the mandibular growth direction is affected not only by the occlusal force but also by environmental factors such as orthodontic treatment, parafunctional habits, and functional malocclusion $[26,27]$.

This study showed that the mandibular ramus height, the mandibular body length, and the condylar width in skeletal class II patients were smaller than those in skeletal class I patients. The growth of the ramus height mainly depends on the new bone apposition in the mandibular condyle. The increase in mandibular body length is mainly due to the apposition of new bone on the lateral aspect of the mandible and the absorption of old bone on the medial aspect. The condyle undergoes cartilaginous growth. These findings suggest that mandibular condylar growth is insufficient, and mandibular body length is underdeveloped in skeletal class II patients.

In skeletal class II, GoR-Me-GoL and CoR-Me-CoL were larger than those in skeletal class I, indicating that the mandibular morphology was more stretched. According to the functional growth theory of the mandible, this change might be a kind of compensation. The growth of the mandible body length is restricted by the functional movements of the masseter, medial pterygoid, and temporalis muscles, relatively 


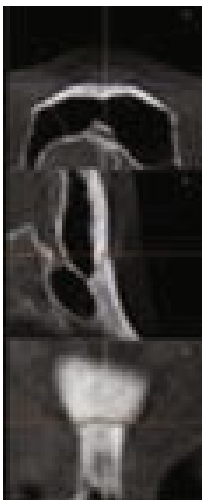

(a)

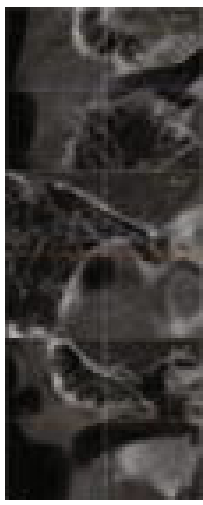

(d)

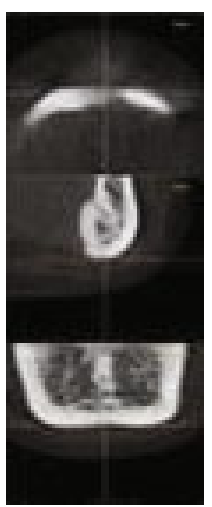

(g)

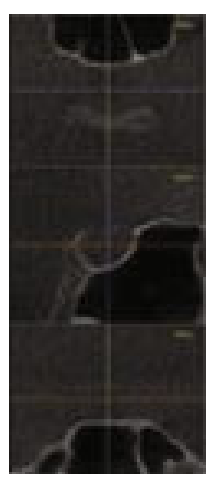

(b)

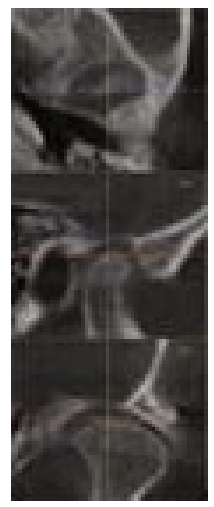

(e)

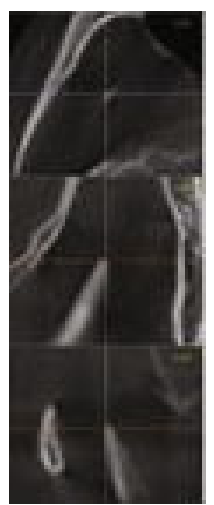

(h)

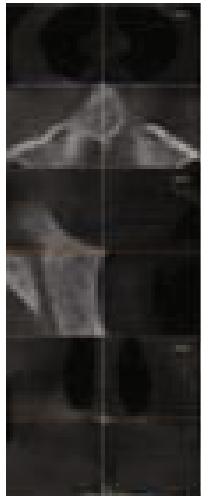

(c)

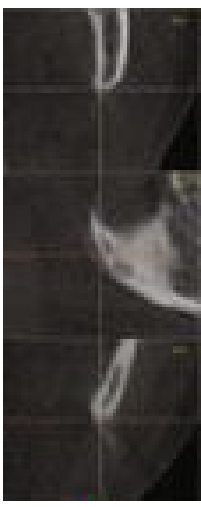

(f)

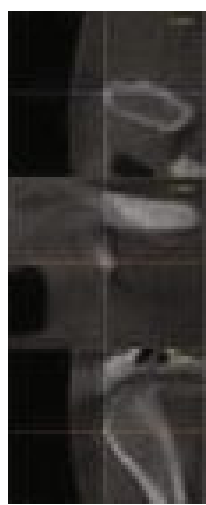

(i)

Figure 1: The 3D positioning maps of (a) N, (b) S, (c) ANS, (d) Po-R, (e) Co-L, (f) Go-L, (g) Men, (h) Cc-R, and (i) CdDR.

increasing bone deposition on the posterior part of the mandible, which decreases the curvature of the mandible.

Mandibular body height mainly depends on the growth of the alveolar process when the mandibular teeth erupt. The mandibular body height in skeletal class II patients is higher than that in skeletal class I patients, indicating that the mandibular anterior alveolar bone is overdeveloped, while the skeletal class II patients are prone to deep overbite. On the other hand, hypoplasia of mandibular body length leads to deep overjet. The anterior teeth do not contact, resulting in their supraspinatus and deep overbite.

Three-dimensional morphological differences of the mandible have their own special features in males and females. The mandibular body length and condyle width of skeletal class II male and female patients were smaller than those in skeletal class I male and female patients, respectively, consistent with the differences between the groups.

The mandibular ramus height and the condylar thickness in skeletal class II female patients were smaller than those in skeletal class I female patients, with no significant differences in these items in males. The growth of the mandibular ramus height ascending branch mainly depends on the apposition of the new bone in the mandibular condyle, which is the growth center of the mandible $[28,29]$. The reason might be that the mandibular 


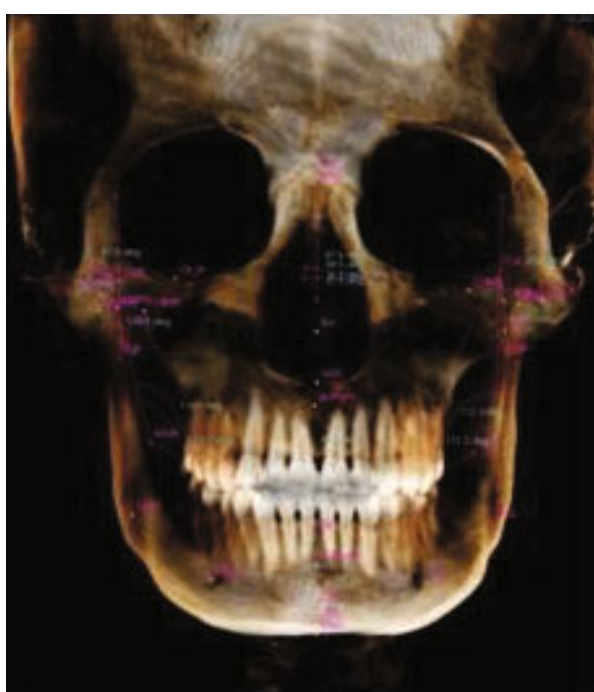

(a)

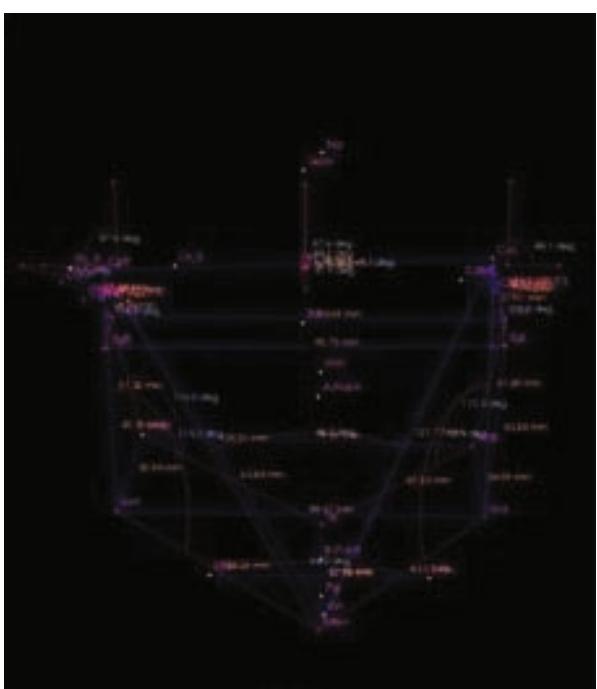

(b)

FIgURE 2: Three-dimensional measurement result of (a) angle and (b) line distance (anterior view).

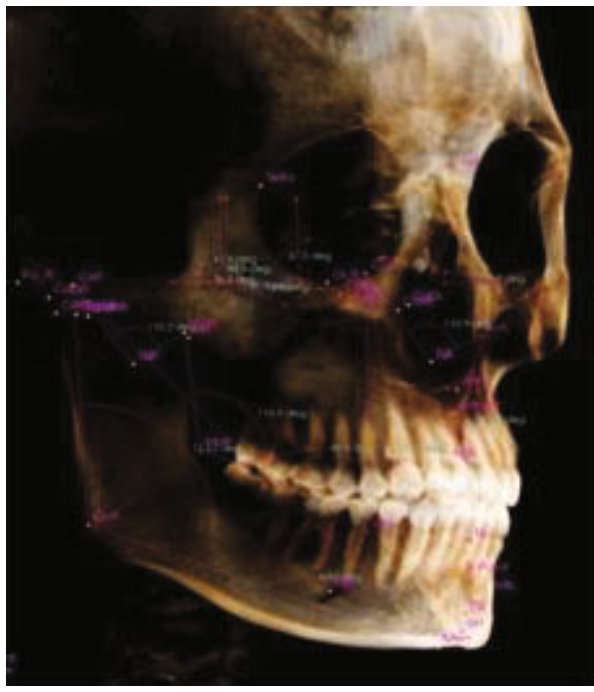

(a)

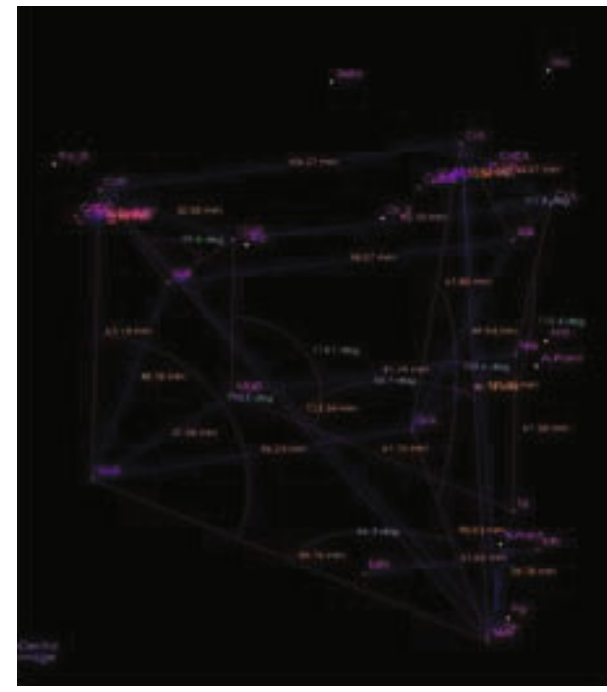

(b)

Figure 3: Three-dimensional measurement result of (a) angle and (b) line distance ( $45^{\circ}$ lateral view).

hypoplasia in females is more significantly affected by genetic factors, and condylar growth deficiency is responsible for this in males.

The opening of the mandibular body relative to $\mathrm{Me}$ and the mandibular body height in skeletal class II male patients were greater than those in skeletal class I male patients, with no significant difference in these items in females. The growth of the mandibular body height mainly depends on the increase in the alveolar process height during the eruption of the mandibular teeth [30]. The reason might be that mandibular hypoplasia in skeletal class II males is more significantly affected by environmental factors, and the compensation of muscles and the alveolar process is the main cause.
There was no significant difference in the distance between paired points, such as the width of the mandibular body and the distance between the sigmoid notch. There was no significant difference in the anteroposterior, mesial, and distal inclination of the ramus and condyle, indicating that the mandible in skeletal class II patients did not affect these items. Bayome et al. scanned the CBCT scans of 38 young adults with normal occlusion and found that the mandible in males was larger than that in females, but the mandibular angle in females was larger [20]. There is a moderate to strong correlation between several vertical and horizontal variables; for example, there is a negative correlation between condylar anteroposterior inclination and mandibular angle and a negative correlation between 


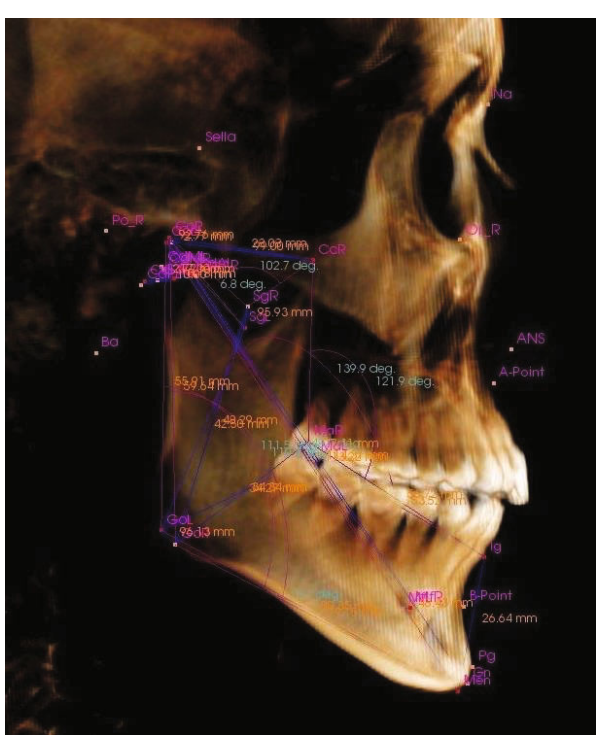

(a)

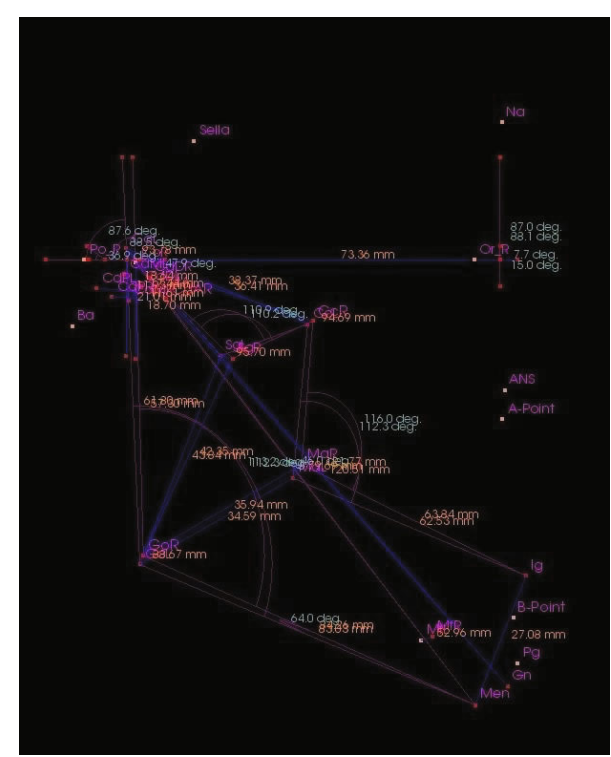

(b)

Figure 4: Three-dimensional measurement result of (a) angle and (b) line distance (lateral view).

TABLE 3: The difference between skeletal class I and skeletal class II $(\bar{x} \pm s)$.

\begin{tabular}{lccc}
\hline Measurement landmark & Skeletal class I & Skeletal class II & $P$ value \\
\hline Co-Go & $61.080 \pm 4.690$ & $57.527 \pm 5.857$ & 0.012 \\
Ig-Men & $29.655 \pm 2.073$ & $31.049 \pm 29.40$ & 0.039 \\
Go-Me & $83.524 \pm 4.242$ & $80.312 \pm 3.413$ & 0.002 \\
CdM-CdD & $19.045 \pm 2.051$ & $17.135 \pm 2.528$ & 0.002 \\
GoR-Me-GoL & $67.779 \pm 4.516$ & $70.586 \pm 4.368$ & 0.017 \\
CoR-Me-CoL & $50.694 \pm 2.951$ & $52.439 \pm 2.661$ & 0.019 \\
\hline
\end{tabular}

TABLE 4: The difference between skeletal class I and skeletal class II in male $(\bar{x} \pm s)$.

\begin{tabular}{lccc}
\hline $\begin{array}{l}\text { Measurement } \\
\text { landmark }\end{array}$ & $\begin{array}{c}\text { Skeletal class I } \\
(\text { male })\end{array}$ & $\begin{array}{c}\text { Skeletal class II } \\
(\text { male })\end{array}$ & $\begin{array}{c}P \\
\text { value }\end{array}$ \\
\hline Go-Me & $84.979 \pm 4.339$ & $81.526 \pm 3.168$ & 0.019 \\
Ig-Men & $30.599 \pm 1.588$ & $33.033 \pm 2.654$ & 0.005 \\
CdM-CdD & $20.086 \pm 1.985$ & $18.326 \pm 2.346$ & 0.035 \\
GoR-Me-GoL & $68.972 \pm 4.252$ & $73.081 \pm 3.518$ & 0.007 \\
\hline
\end{tabular}

the ramus length and mandibular angle. It provides us with further research direction. The three-dimensional measurement of the mandibular shape and position should be further explored, and the pathogenic mechanism and morphological characteristics of skeletal class II patients should be studied to better guide the clinical diagnosis, scheme formulation, and prognosis evaluation in orthodontic treatment, orthognathic surgery, and other fields.
TABLE 5: The difference between skeletal class I and skeletal class II in female $(\bar{x} \pm s)$.

\begin{tabular}{lccc}
\hline $\begin{array}{l}\text { Measurement } \\
\text { landmark }\end{array}$ & $\begin{array}{c}\text { Skeletal class I } \\
\text { (female) }\end{array}$ & $\begin{array}{c}\text { Skeletal class II } \\
\text { (female) }\end{array}$ & $\begin{array}{c}P \\
\text { value }\end{array}$ \\
\hline Go-Me & $82.069 \pm 3.729$ & $79.099 \pm 3.308$ & 0.029 \\
Co-Go & $58.814 \pm 2.599$ & $53.324 \pm 4.150$ & 0.0001 \\
CdM-CdD & $18.005 \pm 1.567$ & $15.943 \pm 2.165$ & 0.006 \\
CdA-CdP & $10.567 \pm 1.370$ & $9.442 \pm 1.401$ & 0.034 \\
\hline
\end{tabular}

\section{Conclusion}

(A) There were statistically significant differences between skeletal class I and class II patients in the three-dimensional morphology of the mandible. The mandibular ramus height, mandibular body length, and condylar width in skeletal class II patients were smaller than those in skeletal class I patients. The mandibular body height in skeletal class II patients was higher than that in skeletal class I patients. The mandibular shape was more extended

(B) CBCT-assisted In Vivo Dental 5.1 software is a practical and effective method to study the threedimensional morphology of the mandible. It can initially form a three-dimensional measurement method of the mandible, accurately describe the mandibular shape three-dimensionally, and guide clinical practice

\section{Data Availability}

The data used to support the findings of this study are available from the corresponding author upon request. 


\section{Conflicts of Interest}

The authors declare no competing interests.

\section{Authors' Contributions}

Qiang Dong, HaoYu Shi, and Qi Jia contributed equally to this work.

\section{References}

[1] S. E. Cassidy, S. R. Jackson, D. L. Turpin, D. S. Ramsay, C. Spiekerman, and G. J. Huang, "Classification and treatment of class II subdivision malocclusions," American Journal of Orthodontics and Dentofacial Orthopedics, vol. 145, no. 4, pp. 443-451, 2014.

[2] L. F. Andrews, "The 6-elements orthodontic philosophy: treatment goals, classification, and rules for treating," American Journal of Orthodontics and Dentofacial Orthopedics, vol. 148, no. 6, pp. 883-887, 2015.

[3] P. Huang, B. Cai, C. Zhou et al., "Contribution of the mandible position to the facial profile perception of a female facial profile: an eye-tracking study," American Journal of Orthodontics and Dentofacial Orthopedics, vol. 156, no. 5, pp. 641-652, 2019.

[4] J. B. Ludlow, M. Gubler, L. Cevidanes, and A. Mol, "Precision of cephalometric landmark identification: cone-beam computed tomography vs conventional cephalometric views," American Journal of Orthodontics and Dentofacial Orthopedics, vol. 136, no. 3, pp. 312.e1-312.e10, 2009.

[5] J. Y. Cha, J. Mah, and P. Sinclair, "Incidental findings in the maxillofacial area with 3-dimensional cone-beam imaging," American Journal of Orthodontics and Dentofacial Orthopedics, vol. 132, no. 1, pp. 7-14, 2007.

[6] D. A. Sanders, P. H. Rigali, W. P. Neace, F. Uribe, and R. Nanda, "Skeletal and dental asymmetries in class II subdivision malocclusions using cone-beam computed tomography," American Journal of Orthodontics and Dentofacial Orthopedics, vol. 138, no. 5, pp. 542.e1-542.e20, 2010

[7] B. Friedland, B. Donoff, and T. B. Dodson, "The use of 3dimensional reconstructions to evaluate the anatomic relationship of the mandibular canal and impacted mandibular third molars," Journal of Oral and Maxillofacial Surgery, vol. 66, no. 8, pp. 1678-1685, 2008.

[8] G. Vinay, S. R. Mangala Gowri, and J. Anbalagan, "Sex determination of human mandible using metrical parameters," Journal of clinical and diagnostic research, vol. 7, pp. 26712673, 2013.

[9] X. Wang, T. Zhang, E. Yang et al., "Biomechanical analysis of grafted and nongrafted maxillary sinus augmentation in the atrophic posterior maxilla with three-dimensional finite element method," Scanning, vol. 2020, Article ID 8419319, 8 pages, 2020.

[10] X. Mao, X. Fu, F. Niu et al., "Three-dimensional analysis of mandibular angle classification and aesthetic evaluation of the lower face in Chinese female adults," Annals of Plastic Surgery, vol. 81, no. 1, pp. 12-17, 2018.

[11] A. Sam, K. Currie, H. Oh, C. Flores-Mir, and M. LagravéreVich, "Reliability of different three-dimensional cephalometric landmarks in cone-beam computed tomography: a systematic review," The Angle Orthodontist, vol. 89, no. 2, pp. 317-332, 2019.
[12] S. Y. Lee, D. S. Choi, I. Jang, G. S. Song, and B. K. Cha, "The genial tubercle: a prospective novel landmark for the diagnosis of mandibular asymmetry," Korean journal of orthodontics, vol. 47 , no. 1 , pp. $50-58,2017$.

[13] L. C. Ardelean, L. C. Rusu, S. G. Stanciu, and J. M. Bueno, "Novel scanning characterization approaches for the accurate understanding and successful treatment of oral and maxillofacial pathologies," Scanning, vol. 2020, Article ID 6545823, 2 pages, 2020.

[14] A. Yilmaz, D. Helvacioglu-Yigit, C. Gur et al., "Evaluation of dentin defect formation during retreatment with hand and rotary instruments: a micro-CT study," Scanning, vol. 2017, Article ID 4868603, 7 pages, 2017.

[15] F. Mangano, C. Mangano, B. Margiani, and O. Admakin, "Combining intraoral and face scans for the design and fabrication of computer-assisted design/computer-assisted manufacturing (CAD/CAM) polyether-ether-ketone (PEEK) implant-supported bars for maxillary overdentures," Scanning, vol. 2019, Article ID 4274715, 14 pages, 2019.

[16] S. Paśko, M. Dzierzęcka, H. Purzyc et al., "The osteometry of equine third phalanx by the use of three-dimensional scanning: new measurement possibilities," Scanning, vol. 2017, Article ID 1378947, 6 pages, 2017.

[17] R. D. Navarro, P. V. Oltramari-Navarro, T. M. Fernandes et al., "Comparison of manual, digital and lateral CBCT cephalometric analyses," Journal of Applied Oral Science, vol. 21, no. 2, pp. $167-176,2013$

[18] C. Oliveira-Santos, A. L. Á. Capelozza, M. S. G. Dezzoti, C. M. Fischer, M. L. Poleti, and I. R. F. Rubira-Bullen, "Visibility of the mandibular canal on CBCT cross-sectional images," Journal of Applied Oral Science, vol. 19, no. 3, pp. 240-243, 2011.

[19] B. Freitas, H. Freitas, P. C. Dos Santos, and G. Janson, "Correction of Angle Class II division 1 malocclusion with a mandibular protraction appliances and multiloop edgewise archwire technique," Korean journal of orthodontics, vol. 44, no. 5, pp. 268-277, 2014.

[20] M. Bayome, J. H. Park, and Y. A. Kook, "New threedimensional cephalometric analyses among adults with a skeletal class I pattern and normal occlusion," Korean journal of orthodontics, vol. 43, no. 2, pp. 62-73, 2013.

[21] R. Generoso, E. C. Sadoco, M. C. Armond, and G. H. Gameiro, "Evaluation of mandibular length in subjects with class I and class II skeletal patterns using the cervical vertebrae maturation," Brazilian Oral Research, vol. 24, no. 1, pp. 46-51, 2010.

[22] K. Katayama, T. Yamaguchi, M. Sugiura, S. Haga, and K. Maki, "Evaluation of mandibular volume using cone-beam computed tomography and correlation with cephalometric values," The Angle Orthodontist, vol. 84, no. 2, pp. 337-342, 2014.

[23] A. T. Karlsen, "Craniofacial growth differences between low and high MP-SN angle males: a longitudinal study," The Angle Orthodontist, vol. 65, no. 5, pp. 341-350, 1995.

[24] M. Ringqvist, "Isometric bite force and its relation to dimensions of the facial skeleton," Acta Odontologica Scandinavica, vol. 31, no. 1, pp. 35-42, 1973.

[25] R. Nair, T. S. Deguchi, X. Li, S. Katashiba, and Y. H. Chan, "Quantitative analysis of the maxilla and the mandible in hyper- and hypodivergent skeletal class II pattern," Orthodontics \& Craniofacial Research, vol. 12, no. 1, pp. 9-13, 2009.

[26] J. A. Alarcón, M. Bastir, A. Rosas, and J. Molero, "Chincup treatment modifies the mandibular shape in children with 
prognathism," American Journal of Orthodontics and Dentofacial Orthopedics, vol. 140, no. 1, pp. 38-43, 2011.

[27] C. van Keulen, G. Martens, and L. Dermaut, "Unilateral posterior crossbite and chin deviation: is there a correlation?," European Journal of Orthodontics, vol. 26, no. 3, pp. 283-288, 2004.

[28] K. S. Arora, R. Bansal, S. Mohapatra, and S. Pareek, "Review and classification update: unilateral condylar hyperplasia," BMJ Case Reports CP, vol. 12, 2019.

[29] R. Patcas, G. Herzog, T. Peltomäki, and G. Markic, "New perspectives on the relationship between mandibular and statural growth," European Journal of Orthodontics, vol. 38, no. 1, pp. 13-21, 2016.

[30] Y. F. Chen, F. Baan, R. Bruggink, E. Bronkhorst, Y. F. Liao, and E. Ongkosuwito, "Three-dimensional characterization of mandibular asymmetry in craniofacial microsomia," Clinical Oral Investigations, vol. 24, no. 12, pp. 4363-4372, 2020. 